\title{
Dublin Core
}

and the

Digital

Repository

of Ireland
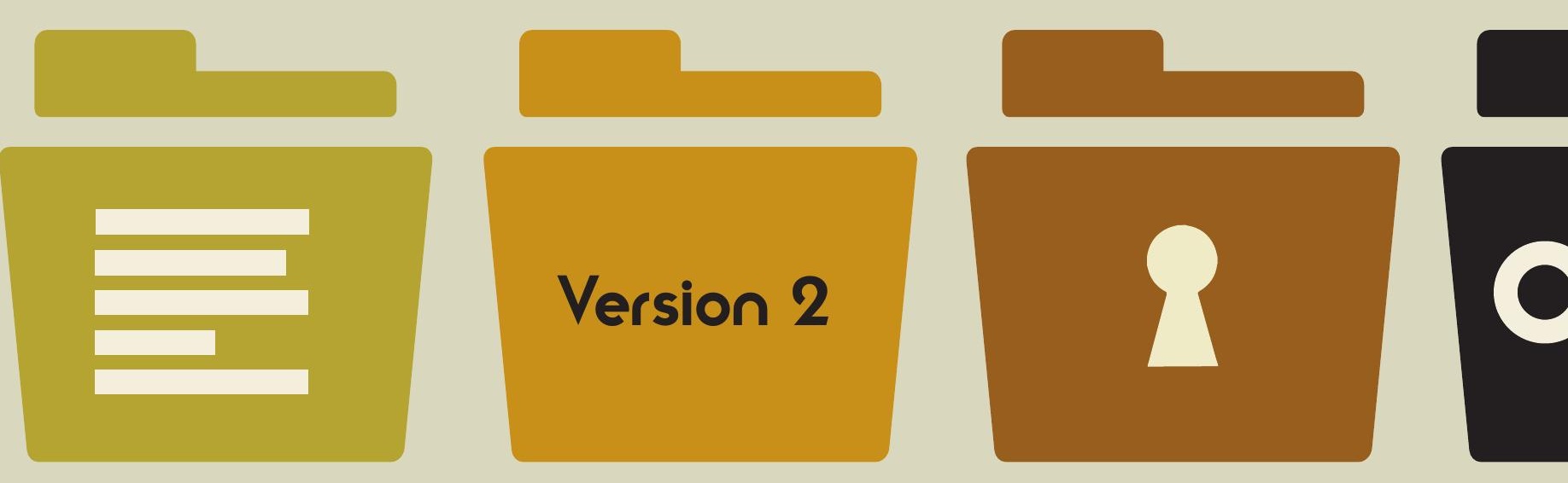

$\mathrm{dri}^{\circ}$ 
Contributors from the Digital Repository of Ireland Metadata Taskforce:

Dr. Marta Bustillo, Assistant Librarian, Metadata Cataloguer, Trinity College Dublin Damien Gallagher, Software Engineer, Maynooth University Rebecca Grant, Digital Archivist, Royal Irish Academy

Dr. Natalie Harrower, Manager, Education and Outreach, Royal Irish Academy

Dr. Stuart Kenny, Software Engineer, Trinity College Dublin

Dr. Rósmáire Ní Cholla, Digital Curator, National University of Ireland, Galway

Dr. Aileen O'Carroll, Policy Manager, Maynooth University

Sinéad Redmond, Software Engineer, Maynooth University

Dr. Sharon Webb, Requirements Analyst, Maynooth University.

Edited by Rebecca Grant.

First published in 2015 by the Royal Irish Academy

(C) Maynooth University, Trinity College Dublin, National University of Ireland, Galway and the Royal Irish Academy

This work is licensed under a Creative Commons Attribution 4.0 International Licence.

When citing or attributing this report please use the following: Bustillo, M., Collins, S., Gallagher, D., Grant, R., Harrower, N., Kenny, S., Ní Cholla, R., O'Carroll, A., Redmond, S. and Webb, S. (2014) Dublin Core and the Digital Repository of Ireland Version 2 (R. Grant, Ed.). Maynooth: Maynooth University; Dublin: Trinity College Dublin; Dublin: Royal Irish Academy; Galway: National University of Ireland, Galway.

DOI: http://dx.doi.org/10.3318/DRI.2015.7

DRI may update its guidelines documentation from time to time as the Repository develops. Please ensure that you are using the most up-to-date version of our documentation by checking our DRI Publications page. 


\section{Foreword}

The Digital Repository of Ireland (DRI) has carried out both broad and deep consultation with key institutions across Ireland to understand their metadata practices and needs. This work began in 2011 and our first findings were published in 20121. In 2013 we established a dedicated task force to consolidate our findings both nationally and internationally, and to begin a programme of guidance for best practice in metadata creation and use. This is the first in what will be an ongoing series of guidelines on metadata, suitable for various data types and disciplines within the broad domains of cultural and social data.

This document provides guidelines for preparing metadata for ingestion into the Digital Repository of Ireland, but we hope its reach will go beyond the DRI, and provide the groundwork for a cohesive and standardised approach to metadata in the Humanities and Qualitative Social Sciences in Ireland. We hope you will use these guidelines in your own institution, and encourage you to share them widely; if we adopt common or standardised metadata practices, we will have greater interoperability between our data collections, which will in turn enable improved and enhanced discovery and richer contextualised cross-collection narratives.

I cannot thank enough the experts from the broad suite of institutions who gave so generously of their time and deep expertise for this common goal. I would also like to thank the DRI team for their meticulous work on this task, which started as a simple but important concept, and grew into a complex and challenging endeavour as we embraced the diversity of data and its management practices. I hope the end result is an easy-to-use guide and reference, and we welcome your use and feedback.

Dr. Sandra Collins

Director of the Digital Repository of Ireland Royal Irish Academy

1 Digital Archiving in Ireland: National Survey of the Humanities and Social Sciences, 2012, http://dri.ie/digital-archiving-in-ireland2012.pdf, last accessed 21 March 2014. 


\section{Acknowledgements}

We would like to thank the following individuals who gave so generously of their time:

Lucy Bell, Functional Director, Data Access at UK Data Archive/UK Data Service

Dr. Libby Bishop, Senior Officer, Research Data Management Support Services, UK Data Archive

Martin Bradley, Archives, Digitisation, Museums and Records Management Consultant

Louise Corti, Associate Director and Head ESDS Qualidata, UK Data Archive

Tom Ensom, Senior Project Officer, Essex Data Repository/UK Data Service

Prof. Hans Walter Gabler, Professor Emeritus, Ludwig-Maximilians-Universität, Munich

Treasa Harkin, Melodies and Images Officer, Irish Traditional Music Archive

Breeda Herlihy, Assistant Librarian, IR Project, University College Cork

Dr. Rene van Horik, Theme Manager, Data Archiving and Networked Services

Dr. William Kilbride, Director, Digital Preservation Coalition

B. Jane Lawson, Metadata Cataloguer, Digital Resources and Imaging Services, Trinity College Dublin

Kate McCarthy, DRI-INSIGHT Digital Archivist, Digital Repository of Ireland

Cathal McCauley, University Librarian, Maynooth University

Dr. Elizabeth Mullins, Lecturer, School of History and Archives, University College Dublin

Hugh Murphy, Senior Librarian, Collection Management Services, Maynooth University

Eoghan Ó Carragáin, Assistant Keeper II, National Library of Ireland

Colum O’Riordan, Archive Administrator, Irish Architectural Archive

Catherine Ryan, Digital Librarian, Digital Repository of Ireland

Jane Stevenson, Archives Hub Manager, Archives Hub

Grace Toland, Librarian, Irish Traditional Music Archive

Prof. Norman Vance, Professor of English Literature, University of Sussex 


\section{Introduction}

These guidelines are aimed at anyone using the Dublin Core metadata standard to prepare content which will be deposited with the Digital Repository of Ireland ("the Repository"). These metadata guidelines do not contradict, or indeed replace, the Dublin Core standard, but should be used in tandem with it to ensure that the metadata can be ingested and searched in the Repository.

By following these guidelines, which include mandatory and recommended elements for ingestion of metadata into the Repository, you will be making your collections more easily searchable in the Repository, and cross-searchable with other DRI collections.

\section{Mandatory and Recommended Elements}

Data must be provided for mandatory elements to enable metadata to be ingested by the Repository; metadata will be automatically rejected by the system if mandatory elements are not included. Recommended elements do not have to be included, but DRI strongly advises that they are completed if possible in order to facilitate searching. The remaining Dublin Core elements are Optional. All submitted elements, whether Mandatory, Recommended or Optional, will be stored and available in the Repository.

\section{What to Catalogue}

DRI recommends following the "one to one" principle of Dublin Core: the principle whereby related but conceptually different entities, for example a painting and a digital image of the painting, are described by separate metadata records. ${ }^{2}$ Metadata for a given object can refer to either the physical object or to the digital surrogate, but the information entered should not be a mixture of both.

\section{Controlled Vocabularies}

Controlled vocabularies are recommended in order to enhance the Repository's search function. Although specific controlled vocabularies are recommended in the tables below, they are not mandatory.

\section{Localised Metadata}

The Repository supports the inclusion of localised metadata by allowing the cataloguer to define the language used. This can be specified for a number of Dublin Core elements via the $\mathrm{xml}:$ lang attribute. The elements that support this feature are: Title, Description, Subject, Coverage, Source and Rights. See the table for "Title" for an example of the xml:lang attribute in use.

\footnotetext{
${ }^{2}$ http://wiki.dublincore.org/index.php/Glossary/One-to-One_Principle, last accessed 21 March 2014.
} 


\section{Ingesting into the Repository}

There are two methods for ingestion:

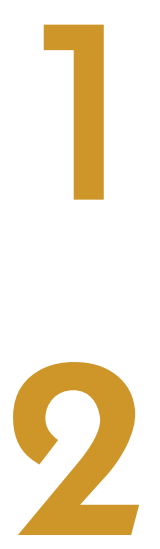

\section{Web Form Ingest}

The Repository includes a web-based user interface for single object ingest. This user interface provides blank fields to allow cataloguers to create metadata for a single digital object. The metadata records are stored as XML and can be exported by the cataloguer as an XML file if desired.

\section{XML Ingest}

Metadata in XML format can also be ingested directly into the Repository. XML metadata must be encoded using UTF-8. The appropriate namespace and schema information must be included in the header of the XML record, for example:

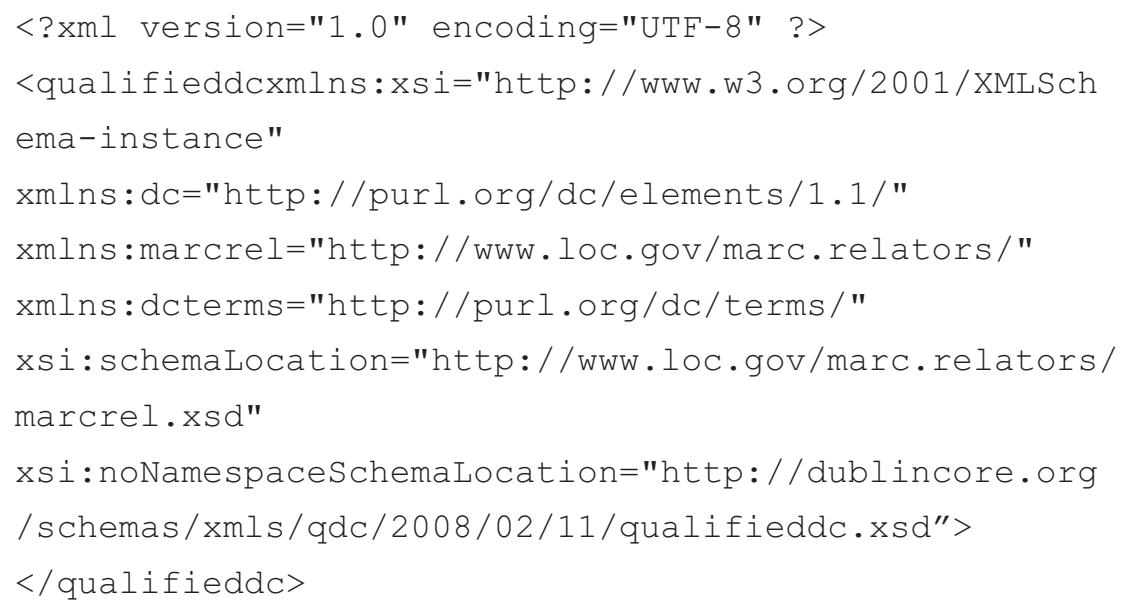

When using XML ingest, in order to match the metadata with its file, the metadata file and digital asset file should use the same filename, e.g. object1.xml and object1.tif.

If there are multiple files associated with the metadata file, follow the filename with an underscore and an alphanumeric sequence, e.g. object2.xml, object2_001.tif, object2_002.tif, object2_003.tif.

\section{Please see the DRI Resources page for further information on ingestion.}

\section{Dublin Core Resources}

The Dublin Core Simple Element Set version 1.1 is currently available here:

Dublin Core Metadata Element Set, Version 1.1.3

Guidance on using Dublin Core for Cataloguing is available here:

Using Dublin Core: The Elements. ${ }^{4}$

\footnotetext{
${ }^{3}$ http://dublincore.org/documents/dces/, last accessed 14 August 2014.

${ }^{4}$ http://dublincore.org/documents/usageguide/elements.shtml\#source, last accessed 14 August 2014.
} 
Table of Mandatory and Recommended elements, and suģgested controlled vocabularies/standards for DRI

\begin{tabular}{llll} 
Element & Obligation & $\begin{array}{c}\text { Suggested } \\
\text { Controlled } \\
\text { Vocabulary }\end{array}$ & Page reference \\
Title & Mandatory & No & 8 \\
\hline Creator & Mandatory & Yes & 8 \\
\hline Date & Mandatory & Yes & 9 \\
\hline Description & Mandatory & No & 10 \\
\hline Rights & Mandatory & No & 10 \\
\hline Type & Mandatory & Yes & 11 \\
\hline Language & Recommended & Yes & 12 \\
\hline Contributor & Recommended & Yes & 12 \\
\hline Relation & Recommended & No & 13 \\
\hline Source & Recommended & No & 13 \\
\hline Coverage & Recommended & Yes & 14 \\
\hline Subject & Recommended & Yes & 15 \\
\hline Identifier & Optional & No & \\
\hline Format & Optional & No & \\
\hline Publisher & Optional & No & \\
\hline
\end{tabular}




\title{
Sample DRI-compliant Dublin Core XML record
}

\author{
$<$ ?xml version="1.0" encoding="UTF-8"?> \\ <metadata xmlns:xsi="http://www.w3.org/2001/XMLSchema-instance" \\ xmlns: dc="http://purl.org/dc/ \\ elements/1.1/" xsi:schemaLocation="http://purl.org/dc/elements/1.1/ \\ $\mathrm{dc} \cdot \mathrm{xsd} \mathrm{d}^{\prime \prime}>$ \\ <dc:title>Caring for Digital Content: Mapping International \\ Approaches</dc:title $>$ \\ $<$ dc:creator $>$ O'Carroll, Aileen $</$ dc:creator $>$ \\ $<$ dc:creator $>$ Webb, Sharon</dc:creator $>$ \\ $<$ dc:creator $>$ Collins, Sandra</dc:creator $>$ \\ $<$ dc:creator $>$ Tang, Jimmy $</ d c$ :creator $>$ \\ $<$ dc:creator $>$ Gallagher, Damien $</$ dc:creator $>$ \\ $\langle$ dc: subject $>$ Archives $</$ dc: subject $>$ \\ $<$ dc: subject $>$ Libraries $</$ dc $:$ subject $>$ \\ $<$ dc:subject $>$ Digital preservation $</$ dc:subject $>$ \\ $<$ dc:subject>Digital archiving</dc:subject $>$ \\ $<$ dc: description>This report from the Digital Repository of Ireland maps \\ emerging international approaches to caring for digital content. The \\ repositories selected fall into three categories: the metadata \\ aggregator, the single-site repository, and the multi-site repository. \\ the report documents key developments in the field, key organisations \\ and information providers from different domains, and includes a brief \\ overview of current EU digital preservation projects.</dc:description> \\ <dc:publisher>Digital Repository of Ireland</dc:publisher > \\ $<$ dc: date $>$ name=September 2013; start=2013-09-01; end=2013-09-30 \\ $</$ dc: date $>$ \\ $<$ dc: type $>$ Text $</$ dc $:$ type $>$ \\ $<$ dc: format $>\mathrm{PDF}</ \mathrm{dc}:$ format $>$ \\ <dc:identifier>DOI: $10.3318 /$ DRI.2013.1</dc:identifier> \\ $<$ dc: language $>\mathrm{EN}</$ dc: language $>$ \\ <dc:rights>Copyright Maynooth University, Trinity College Dublin, and \\ the Royal Irish Academy. All rights reserved. No part of this book may \\ be reprinted or reproduced or utilised in any electronic, mechanical \\ or any other means, now known or hereafter invented, including \\ photocopying and recording, or otherwise without either the prior \\ written consent of the publishers or a licence permitting restricted \\ copying in Ireland issued by the Irish Copyright Licensing Agency Ltd, \\ The Writers' Centre, 19 Parnell Square, Dublin 1</dc:rights>
}

$</$ metadata $>$ 


\section{Key to the Tables:}

Label

This is the name of the metadata element taken from the

Dublin Core documentation, for example "Title".

Metadata Element

This is the Dublin Core XML encoding of the metadata

element, for example dc: title

The metadata elements described in these guidelines use

the namespace prefix dc: for every element.

Definition

This is the formal definition of the element, taken from

the Dublin Core documentation.

Format of content This is the type of data entered in the metadata element, for example free text, or a suggested controlled vocabulary.

Obligation

This field details whether or not the element is a required

field for ingest into the Repository. Elements are

designated as either Mandatory or Recommended.

Optional elements are not detailed in this document as

they do not have DRI- specific recommendations

associated with them.

Repeatable

This field details whether or not the metadata standard allows more than one use of the metadata element. For example, if it is possible to enter more than one Subject the element is repeatable, e.g.

$<$ dc: subject $>$ Cow $</$ dc : subject $>$

$<$ dc: subject $>$ Mammal $</$ dc : subject $>$

All Dublin Core elements are repeatable. 


\section{Mandatory Elements}

\begin{tabular}{|c|c|}
\hline Label & Title $^{5}$ \\
\hline Metadata Element & dc:title \\
\hline Definition & $\begin{array}{l}\text { A name given to the resource. Typically, a Title will be a } \\
\text { name by which the resource is formally known. }\end{array}$ \\
\hline Format of content & Free text \\
\hline Obligation & Mandatory \\
\hline Repeatable & Yes \\
\hline \multirow[t]{8}{*}{ Values (examples) } & $<$ dc:title $>$ Ulysses $</$ dc:title $>$ \\
\hline & <dc:title>Childhood in Ireland: A Qualitative \\
\hline & Study</dc:title $>$ \\
\hline & <dc:title>The Morning Show</dc:title $>$ \\
\hline & Example of an object with multiple titles \\
\hline & <dc:title>The Three Musketeers</dc:title $>$ \\
\hline & <dc:title xml:lang="fr">Les Trois \\
\hline & Mousquetaires</dc:title $>$ \\
\hline Label & Creator 6 \\
\hline Metadata Element & dc:creator \\
\hline Definition & $\begin{array}{l}\text { An entity primarily responsible for making the content of the } \\
\text { resource. Examples of a Creator include a person, an } \\
\text { organization, or a service. Typically the name of the Creator } \\
\text { should be used to indicate the entity. }\end{array}$ \\
\hline Format of content & $\begin{array}{l}\text { Personal, family and corporate names should preferably be } \\
\text { formatted according to the Irish Guidelines for Indexing Archives. }{ }^{7}\end{array}$ \\
\hline Obligation & Mandatory \\
\hline Repeatable & Yes \\
\hline \multirow[t]{2}{*}{ Values (examples) } & $\begin{array}{l}<\text { dc:creator }>\text { Joyce, James, } 1882-1941</ \text { dc:creator }> \\
<\text { dc:creator }>\text { Irish Qualitative Data Archive, Maynooth } \\
\text { University</dc:creator }>\end{array}$ \\
\hline & <dc:creator $>$ Radio na Gaeltachta, 1972-</dc:creator $>$ \\
\hline Notes & $\begin{array}{l}\text { For Irish family names, such as Mary Choilm a' tSeaimpín, } \\
\text { where Choilm a' tSeaimpín is a family identifier rather than a } \\
\text { surname and cannot precede Mary, DRI suggests that the } \\
\text { family identifier should follow the first name. } \\
\text { If the creator is unknown, some term should be entered in } \\
\text { the Creator element to signal this, such as "Unknown" or } \\
\text { "Anonymous". However, if the cataloguer would prefer to } \\
\text { leave the element blank, they should fill in "null". }\end{array}$ \\
\hline
\end{tabular}




\section{Mandatory Elements}

\section{Label \\ Metadata Element \\ Definition}

Format of content

\section{Obligation}

Repeatable

Values (examples)

\section{Date $^{8}$}

dc:date

A point or period of time associated with an event in the lifecycle of the resource.

Date should preferably be formatted according to the W3C Note on Date and Time Formats ${ }^{9}$, ISO $8601^{10}$ or the DCMI Period Encoding Scheme. ${ }^{11}$

Mandatory

Yes

<dc:date>2013-11-05</dc:date>

$<$ dc $:$ date $>$ name $=1960 \mathrm{~s} ;$ start $=1960-01-01$;

end=1969-12-31; </dc: date $>$

Notes

Date may refer to published date, broadcast date, object creation date, etc.

If you need to accurately identify the date type then please consider using Qualified Dublin Core.

If the date is unknown and the cataloguer would prefer to leave the element blank rather than write "Unknown," they should fill in "null".

The Repository supports the inclusion of date spans encoded as DCMI Period, and will also index uncertain dates which are prefaced by "circa" or "ca" if the desired date range is encoded appropriately. If the desired display date is "circa 1935" then it could for example be encoded with a ten year span (1930-1940) and would then be searchable by any date within this span. Although the span is indexed for search, the display date defined as name $=$ will be the only part of the date which is displayed by the Repository.

The encoding scheme used (either W3C-DTF or ISO 8601) must be included.

For example:

$<$ dc:date xsi:type="dcterms:Period" $>$ name=ca

1935 ;

start=1930-01-01; end=1940-12-31;

scheme=W3CDTF $;</$ dc $:$ date $>$

$<$ dc:date xsi:type="dcterms:Period" $>$ name=ca

1860 ;

start=1855-01-01; end=1865-12-31;

scheme $=\operatorname{IS0} 8601 ;</$ dc $:$ date $>$

$8 \mathrm{http} / / /$ purl.org/dc/elements/1.1/date, last accessed 14 August 2014.

${ }^{9} \mathrm{http}: / /$ www.w3.org/TR/NOTE-datetime, last accessed 14 August 2014.

${ }^{10} \mathrm{http}: / / \mathrm{www}$.iso.org/iso/home/standards/iso8601.htm, last accessed 14 August 2014.

$11 \mathrm{http}: / /$ dublincore.org/documents/dcmi-period/, last accessed 14 August 2014. 


\section{Mandatory Elements}

Label
Metadata Element
Definition
Format of content
Obligation
Repeatable
Values (examples)

Notes
Description $^{12}$

dc: description

An account of the resource.

Free text

Mandatory

Yes

$<$ dc:description $>$ A novel about the fictional character Leopold Bloom in early twentieth-century Dublin that mirrors the wanderings of the Ulysses

epic.</dc:description>

<dc:description>Linked Logainm is a collaborative project led by the Digital Repository of Ireland (DRI), INSIGHT at NUI Galway, Fiontar at Dublin City University, and the National Library of Ireland. The Linked Logainm project created a Linked Data version of the authoritative bilingual database of Irish place names logainm.ie, developed by Fiontar in collaboration with the Placenames Branch of the Department of Arts,Heritage and the Gaeltacht. \&\#xA; The publication of logainm.ie data in a structured, computer-readable format allows its value to be reused by computer scientists, web developers, the heritage community and information professionals.\&\#xA; \&\#xA; The project document "Using the Linked Logainm Dataset" provides use-cases and examples for those who are interested in working with the Linked Logainm dataset, and who have some technical experience.</dc:description>

Description may include but is not limited to: an abstract, a table of contents, or a free-text account of the resource.

For long descriptions, the Repository supports the inclusion of paragraphs and line breaks. When using the ingest form, pressing return will create a line break which will be displayed in the Repository's user interface. Pressing return twice will create a new paragraph. When creating XML metadata, \&\#xD; may be used to create a carriage return, while \&\#xA; will create a line break. The inclusion of two carriage returns or line breaks consecutively, for example \&\#xA;\&\#xA; will create a paragraph break. 
Label

Metadata Element

Definition

Format of content

Obligation

Repeatable

Values (examples)

\section{Rights ${ }^{13}$}

dc:rights

Information about rights held in and over the resource. Typically a Rights element will contain a rights management statement for the resource, or reference a service providing such information. Rights information often encompasses Intellectual Property Rights (IPR), Copyright, and various Property Rights.

Free text

Mandatory

Yes

$<$ dc:rights>Copyright National Library of Ireland, $2013</$ dc:rights $>$

<dc:rights>Copyright IQDA, Maynooth University. All

rights reserved $</$ dc:rights $>$

<dc:rights>Copyright Radio na Gaeltachta. This work is licensed under a Creative Commons Attribution-

NoDerivs 3.0 Ireland Licence. Please use the

following attribution when citing this work:

Copyright Radio na Gaeltachta, digital surrogate

created by the DRI NUI Galway Demonstrator

Project</dc:rights $>$

Notes

how the resource can be reused.

\section{Mandatory Elements}
Label
Metadata Element
Definition

Format of content

Obligation

Repeatable

Values (examples)
Type $^{14}$

dc:type

The nature or genre of the content of the resource. Type includes terms describing general categories, functions, genres, or aggregation levels for content.

Free text

Recommended controlled vocabularies for this element:

DCMI Type Vocabulary. ${ }^{15}$

Other recommended vocabularies are available on the

DRI Vocabularies page. ${ }^{16}$

Mandatory

Yes

$$
\begin{aligned}
& <\text { dc }: \text { type }>\text { Dataset</dc : type }> \\
& <\text { dc: type }>\text { Moving Image }</ \text { dc: type }> \\
& <\text { dc }: \text { type }>\text { Text }</ \text { dc }: \text { type }> \\
& <\text { dc: type }>\text { Newspapers }</ \text { dc: type }> \\
& <\text { dc: type }>\text { Periodicals }</ \text { dc }: \text { type }>
\end{aligned}
$$




\section{Recommended Elements}

\begin{tabular}{|c|c|}
\hline Label & Language $^{17}$ \\
\hline Metadata Element & dc:language \\
\hline Definition & A language of the resource. \\
\hline Format of Content & $\begin{array}{l}\text { Languages should preferably be formatted according to } \\
\text { ISO } 639^{18} \text { or RFC5646. }{ }^{19}\end{array}$ \\
\hline Obligation & Recommended \\
\hline Repeatable & Yes \\
\hline \multirow[t]{4}{*}{ Values (examples) } & $<$ dc: language $>$ en $</$ dc: $:$ anguage $>$ \\
\hline & $<$ dc: language $>$ eng <dc: language $>$ \\
\hline & $<$ dc: language $>$ ga $</$ dc: $:$ anguage $>$ \\
\hline & $<$ dc: language $>$ gle $<$ dc: language $>$ \\
\hline
\end{tabular}

\begin{tabular}{|c|c|}
\hline Label & Contributor ${ }^{20}$ \\
\hline Metadata Element & dc:contributor \\
\hline Definition & $\begin{array}{l}\text { An entity responsible for making contributions to the } \\
\text { resource. }\end{array}$ \\
\hline Format of content & $\begin{array}{l}\text { Free text. } \\
\text { Personal, family and corporate names should preferably be } \\
\text { formatted according to the Irish Guidelines for } \\
\text { Indexing Archives. }{ }^{21}\end{array}$ \\
\hline Obligation & Recommended \\
\hline Repeatable & Yes \\
\hline Values (examples) & $\begin{array}{l}\text { <dc:contributor>Joyce, James, 1882- } \\
1941</ \text { dc:contributor }> \\
<\text { dc:contributor>Heaney, Seamus, 1939- } \\
2013</ \text { dc:contributor }>\end{array}$ \\
\hline Notes & $\begin{array}{l}\text { Contributors may include interviewees, presenter, } \\
\text { co-presenter, a participant, funders. If you require more } \\
\text { granular descriptions of roles consider using Qualified } \\
\text { Dublin Core. }\end{array}$ \\
\hline
\end{tabular}

\footnotetext{
$17 \mathrm{http}: / /$ purl.org/dc/elements/1.1/language, last accessed 14 August 2014.

${ }^{18} \mathrm{http}: / /$ www.loc.gov/standards/iso639-2/php/code_list.php, last accessed 14 August 2014.

${ }^{19} \mathrm{http}: / /$ tools.ietf.org/html/rfc5646, last accessed 14 August 2014.

$20 \mathrm{http}: / /$ purl.org/dc/elements/1.1/contributor, last accessed 14 August 2014.

${ }^{21} \mathrm{http}: / /$ www.learnaboutarchives.ie/ learnabo/images/documents/ARAlndexing.pdf, last accessed 14 August 2014.
} 


\section{Recommended Elements}

\begin{tabular}{|c|c|}
\hline Label & Relation ${ }^{22}$ \\
\hline Metadata Element & dc:relation \\
\hline Definition & $\begin{array}{l}\text { A reference to a related resource. Recommended best } \\
\text { practice is to reference the resource by means of a string or number } \\
\text { conforming to a formal identification system. }\end{array}$ \\
\hline Format of content & Free text \\
\hline Obligation & Recommended \\
\hline Repeatable & Yes \\
\hline Values (example) & $\begin{array}{l}<\mathrm{dc}: \text { relation }>\text { DOI: } 10.3318 / \mathrm{DRI} .2013 .1</ \text { dc:relation }> \\
<\mathrm{dc}: \text { relation }>\text { This text is a translation of } \\
\text { DOI: } 10.3318 / \mathrm{DRI} . \text { LODer.2013.3</dc:relation }>\end{array}$ \\
\hline Notes & $\begin{array}{l}\text { DOIs, URLS, and library codes or references to demonstrate a } \\
\text { relationship between objects may be included in this element. If you } \\
\text { need to identify more granular relationship types consider using } \\
\text { Qualified Dublin Core. }\end{array}$ \\
\hline Label & Source ${ }^{23}$ \\
\hline Metadata Element & dc:source \\
\hline Definition & A related resource from which the described resource is derived. \\
\hline Format of content & Free text \\
\hline Obligation & Recommended \\
\hline Repeatable & Yes \\
\hline Values (examples) & $\begin{array}{l}<\mathrm{dc} \text { : source>Book of Kells }</ d c: \text { source }> \\
<\mathrm{dc} \text { : source>John Kelly interview</dc: source }>\end{array}$ \\
\hline Notes & $\begin{array}{l}\text { DOIs, URLs, and library codes or references to demonstrate a } \\
\text { relationship between objects may be included in this element. }\end{array}$ \\
\hline
\end{tabular}

\footnotetext{
22 http://purl.org/dc/elements/1.1/relation, last accessed 14 August 2014.

${ }^{23} \mathrm{http}: / /$ purl.org/dc/elements/1.1/source, last accessed 14 August 2014.
} 


\section{Recommended Elements}

\begin{tabular}{|c|c|}
\hline Label & Coverage $^{24}$ \\
\hline Metadata Element & dc: coverage \\
\hline Definition & $\begin{array}{l}\text { The spatial or temporal topic of the resource, the spatial } \\
\text { applicability of the resource, or the jurisdiction under which the } \\
\text { resource is relevant. }\end{array}$ \\
\hline \multirow[t]{8}{*}{ Format of content } & Free text. \\
\hline & Geo-codes should preferably be formatted according to the DCMI \\
\hline & Point Encoding Scheme ${ }^{25}$, and the DCMI Box Encoding \\
\hline & Scheme. ${ }^{26}$ \\
\hline & Temporal data should preferably be formatted according to the \\
\hline & DCMI Period Encoding Scheme ${ }^{27}$, W3C Note on Date and Time \\
\hline & Formats ${ }^{28}$ or ISO $8601^{29}$; or the Library of Congress Subject \\
\hline & Headings for named periods ${ }^{30}$. \\
\hline Obligation & Recommended \\
\hline Repeatable & Yes \\
\hline \multirow[t]{14}{*}{ Values (examples) } & $<$ dc: coverage $>1918-11-11</$ dc $:$ coverage $>$ \\
\hline & $<$ dc: coverage $>$ name $=$ The $1960 \mathrm{~s} ;$ start $=1960-01-01$; \\
\hline & end $=1969-12-31 ;<$ dc $:$ coverage $>$ \\
\hline & $<$ dc:coverage $>$ Early Modern History $</$ dc: coverage $>$ \\
\hline & $<$ dc: coverage $>$ Spain</dc: coverage</dc: coverage $>$ \\
\hline & $<$ dc: coverage $>$ name=Western Australia; northlimit=- \\
\hline & $13.5 ;$ southlimit $=-35.5$; \\
\hline & westlimit $=112.5$; eastlimit $=129</$ dc : coverage $>$ \\
\hline & <dc:coverage>http://data.logainm.ie/place/49237</ \\
\hline & dc $:$ coverage> \\
\hline & <dc:coverage>http://sws.geonames.org/3301443/</ \\
\hline & dc: coverage> \\
\hline & <dc: coverage >http://id.worldcat.org/fast/1271105</ \\
\hline & dc: coverage> \\
\hline
\end{tabular}

\footnotetext{
${ }^{24} \mathrm{http} / / /$ purl.org/dc/elements/1.1/coverage, last accessed 14 August 2014.

25 http://dublincore.org/documents/dcmi-point/, last accessed 14 August 2014.

${ }^{26} \mathrm{http} / / /$ dublincore.org/documents/dcmi-box/, last accessed 14 August 2014.

$27 \mathrm{http} / / /$ dublincore.org/documents/dcmi-period/, last accessed 14 August 2014.

$28 \mathrm{http}: / /$ www.w3.org/TR/NOTE-datetime, last accessed 14 August 2014.

${ }^{29} \mathrm{http}: / / \mathrm{www}$.iso.org/iso/home/standards/iso8601.htm, last accessed 14 August 2014.

30 http://id.loc.gov/authorities/subjects.html, last accessed 21 March 2014.
} 


\section{Recommended Elements}

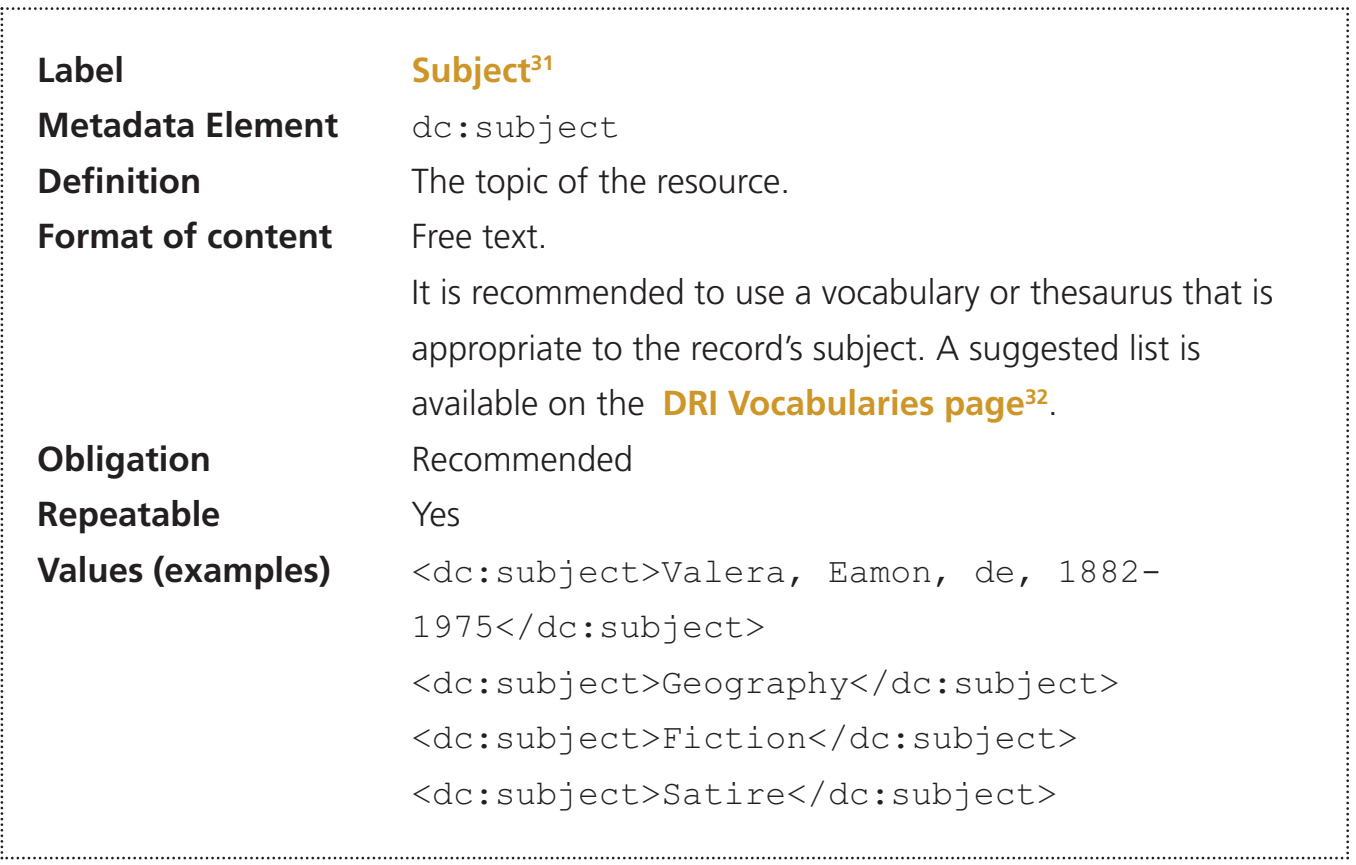

\footnotetext{
${ }^{31}$ http://purl.org/dc/elements/1.1/subject, last accessed 14 August 2014.

${ }^{32} \mathrm{http}: / /$ dri.ie/vocabularies, last accessed 14 August 2014.
} 
